\title{
TEACHERS' ATTITUDES TOWARDS STUDENTS WITH AUTISM SPECTRUM DISORDERS
}

\author{
Nadezhda V. Shuvalova ${ }^{1 *}$, Svetlana V. Lezhenina ${ }^{2}$, Tatiana M. Kozhanova ${ }^{3}$, Mikhail \\ Yu. Sapozhnikov ${ }^{4}$, Evgenia V. Sapozhnikova ${ }^{5}$, Larisa A. Dukina ${ }^{6}$ \\ ${ }^{1}$ Prof, Chuvash State Pedagogical University, RUSSIA, naukacgu@gmail.com \\ ${ }^{2}$ Assoc. Prof., Chuvash State University, RUSSIA, svl-8@bk.ru \\ ${ }^{3}$ Assoc. Prof., Chuvash State Pedagogical University, RUSSIA, kuez-nir2@bk.ru \\ ${ }^{4}$ Prof, Chuvash State University, RUSSIA, alina280695@gmail.com \\ ${ }^{5}$ Assoc. Prof., Chuvash State University, RUSSIA, priem kuez@chuvsu.ru \\ ${ }^{6}$ Assoc. Prof., Chuvash State Pedagogical University, RUSSIA, kuez-nir1@bk.ru \\ ${ }^{*}$ Corresponding Author
}

\begin{abstract}
The article considers the problem of inclusive education through the prism of teachers' attitude to students with autism spectrum disorders. In the modern world, more and more professional requirements are imposed on the teacher. He or she must plan and effectively implement algorithms for solving the assigned tasks. Among the main tasks is the teacher's preparedness to work with a diverse contingent of children with disabilities. The aim of the research was to study the teachers' attitude towards students with autism spectrum disorders (ASD). It involved 152 teachers of educational schools (the second level of education) working in the city of Cheboksary, the Chuvash Republic, the Russian Federation. The interviewquestionnaire period was 2017-2019. The age of the subjects ranged from 23 to 62 years. A specially designed interview-questionnaire was used. The research showed mixed results. On the one hand, most of the teachers (57.2\%) expressed a positive attitude towards inclusive education of students with ASD, a third of respondents expressed a neutral attitude, and only a tenth expressed their negative attitude towards students with ASD. However, despite the positive attitude, two-thirds of the teachers surveyed believed that children with ASD should study in special (correctional) educational institutions and not in classes with healthy children. Also noteworthy are the results obtained regarding the problem of including students with ASD in inclusive education. Slightly more than half of the teachers expressed their fear that children with ASD will not learn what they could learn in a special institution; a third of teachers noted the fear that students without health limitations will be infringed on their rights, and they will be given less time to master the program. Finally, with regard to the teachers' desire to work with students with autism spectrum disorders, almost half of the teachers expressed their reluctance to work with such children. Perhaps this reluctance is due to the insufficient teachers' awareness level about students with ASD. This fact does not put an end to this issue and aims at further research.
\end{abstract}

Keywords: Teachers' attitude, students, autism spectrum disorders, inclusive education. 


\section{INTRODUCTION}

In the modern world, more and more professional requirements are imposed on the teacher. He or she must plan and effectively implement algorithms for solving the assigned tasks. Among the main tasks is the teacher's preparedness to work with a diverse contingent of children with disabilities (Bolte, Hallmayer, 2011; Roberts, Keane and Clark, 2012, pp. 1001-1017).

Autism spectrum disorder (ASD) is a neurobiological disorder, which symptoms persist and change throughout life. Therapy for young children is aimed at correcting neuropsychic development, while in adolescents these techniques are aimed at maintaining order in the living space and achieving independence. As they grow older, the nature of assistance is increasingly shifting towards the socialization of active communication and the independence achievement, including through higher education and job search (Abkovich, 2017, 270 p.; Ayvazyan, 2018). Most researchers confirm that not only patients with ASD need help, but also their parents (Alekseeva, Volkov and Shargorodskaya, 2013, pp. 185-189; Nikolskaya, Baenskaya and Liebling, 1997, 341 p.; Babkina, 2016, pp. 56-61).

The issue of organizing education and socialization of children with ASD in the context of inclusive education in a general education school is especially acute. This is due to the fact that the number of children with ASD in educational institutions is constantly increasing. Consequently, many questions arise regarding the education organization for children with ASD (Babkina, 2017, pp. 138-156; Babkina, 2015, 136 p.; Babkina, 2017, 263 p.).

The aim of the research is to study the teachers' attitude towards students with autism spectrum disorders in the context of inclusive education.

\section{MATERIALS AND RESEARCH METHODS}

The study involved 152 teachers of educational schools (second level of education) working in the city of Cheboksary, the Chuvash Republic. It involved 152 teachers of educational schools (the second level of education) working in the city of Cheboksary, the Chuvash Republic, the Russian Federation. Period of the interview-questionnaire was 2017-2019. The age of the subjects ranged from 23 to 62 years (average age $45.5+/-7.5$ years).

When analyzing the work experience, it was revealed that from 0 to 5 years was noted by $11(7.2 \%)$ people, from 5 to 10 years - by 16 (10.5\%) subjects, from 10 to 20 years - by $23(15,2 \%)$, from 20 to 30 - by 81 (53.3\%), 30 and more - by $21(13.8 \%)$.

To analyze the assessment of the teachers' attitude towards students with autism spectrum disorders, we developed an interview-questionnaire consisting of five questions:

1. What is your attitude towards inclusive education for students with ASD?

2. Where do you think children with ASD should study?

3. Do students with ASD need a tutor?

4. What problems do you see for the inclusion of students with ASD in inclusive education?

5. Do you want to work with children with ASD in an inclusive education setting?

\section{RESEARCH RESULTS}

When asked what is your attitude towards inclusive education of students with ASD, the following results were obtained: $87(57.2 \%)$ respondents expressed a positive attitude towards inclusive education of students with ASD. 150 (32.9\%) people noted a neutral attitude. 15 (9.9\%) teachers indicated a negative attitude.

When asked how you think where children with ASD should study, the answers were distributed as follows: the largest number of answers, $108(71.1 \%)$, was attributed to the special education system, that is, children with ASD should study in special (correctional) educational organizations. In any educational organization, $26(17.1 \%)$ respondents believe, in boarding schools - $16(10.5 \%)$ teachers, individual home education -2 (1.3\%) respondents.

Analysis of answers to the question "Do students with ASD need a tutor?" showed that positive answers were given by $128(84.2 \%)$ respondents, $9(5.9 \%)$ teachers answered negatively, $15(9.9 \%)$ respondents did not know.

When asked what problems you see for the inclusion of students with ASD in inclusive education, the 
answers were distributed as follows: 79 (52\%) teachers expressed their fear that children with ASD would not learn what they could learn in a special institution; 44 (28.9\%) teachers noted the fear that students without health limitations will be infringed on their rights, and they will be given less time to master the program. $13(8.6 \%)$ teachers noted that parents of normotypical children would be against inclusive education, $3(2 \%)$ respondents pointed to the fear and hostility of teachers towards children with autism spectrum disorders, $7(4.6 \%)$ teachers indicated not the lack of tutors and $6(3.9 \%)$ of the respondents consider the psychological readiness of teachers to be insufficient.

When asked whether you want to work with children with ASD in an inclusive education, $72(47.4 \%)$ teachers do not want to work with students with ASD, $33(21.7 \%)$ respondents are afraid, $32(21.1 \%)$ teachers find it difficult to answer this question, 15 (9.9\%) want to work with children with ASD in an inclusive education.

Considering the current state of the problem of teaching children with autism spectrum disorders (ASD) in the context of inclusive education, we would like to note its insufficient solution on the territory of the Russian Federation. As L.V. Shargorodskaya, in our country for a long time children with ASD were not included in the national education system, and for them the main forms of education were hospital care in the health care and social security systems. Gradually, starting in the nineties of the twentieth century, children with ASD began to be admitted to educational institutions, but most often they studied in an individual, home or family form. Specialized teaching in a group form was organized in centers of psychological, medical and social support or in home education schools.

The problems of the specialists' psychology in the conditions of inclusive education remain unresolved. (S.V. Alekhina, R.V. Demyanchuk, E.S.Sukhoterina et al.). Nevertheless, the majority of Russian general education schools turned out to be not quite ready to implement inclusive education on a large scale (outside of educational organizations that had previously chosen the path of appropriate experimental development for themselves). It is important to note that the reasons for this are not limited to psychological problems of acceptance of inclusion by teachers and their lack of professional training.

\section{CONCLUSIONS}

The research obtained mixed results. On the one hand, most of the teachers (57.2\%) expressed a positive attitude towards inclusive education of students with ASD, a third of respondents expressed a neutral attitude, and only a tenth expressed their negative attitude towards students with ASD. However, despite the positive attitude, two-thirds of the teachers surveyed believed that children with ASD should study in special (correctional) educational institutions and not in classes with healthy children. Also noteworthy are the results obtained regarding the problem of including students with ASD in inclusive education. Slightly more than half of the teachers expressed their fear that children with ASD will not learn what they could learn in a special institution; a third of teachers noted the fear that students without health limitations will be infringed on their rights, and they will be given less time to master the program. Finally, with regard to the teachers' desire to work with students with autism spectrum disorders, almost half of the teachers expressed their reluctance to work with such children. Perhaps this reluctance is due to the insufficient level of awareness of teachers about students with ASD. This fact does not put an end to this issue and aims at further research.

\section{REFERENCE LIST}

Abkovich, A. Ya. (2017). Psychological and pedagogical conditions for the inclusion of younger schoolchildren with motor impairments.

Alekseeva, V. V., Volkov, A. A. and Shargorodskaya, L .V. (2013). Ensuring the accessibility of education and socialization of children with ASD and pronounced problems of behavior in the context of a comprehensive school. Inclusive education: practice, research, methodology: collection of articles. materials of the II International Scientific and Practical Conference.

Ayvazyan, E. B. (2018). Research of communication between an adult and a child with disabilities in the first years of life: methodological tools. Almanac of the Institute of Correctional Pedagogy, 32. https://alldef.ru/ru/articles/almanac-32/a-study-of-adult-child-communication-the-first-years-of-life-withdisabilities-a-methodological-toolki

Babkina N. V. (2017). Psychological support of junior schoolchildren with mental retardation. 
Babkina, N. V. (2015). Assessment of school readiness of children with mental retardation. School Book.

Babkina, N. V. (2016). Modern approaches to assessing the achievements and difficulties of junior schoolchildren with mental retardation. Pedagogy and Psychology of Education, 3.

Babkina, N. V. (2017). Life competencies as an integral part of the educational content of children with mental retardation. Clinical and Specialty Psychology, vol. 6, 1. DOI: 10.17759/cpse.2017060109

Bolte, S., Hallmayer, J. (2011). Autism spectrum conditions: FAQ on autism, Asperger syndrome, and atypical autism answered by international experts.

Nikolskaya, O. S., Baenskaya, E. R. and Liebling, M.M. (1997). Autistic child: ways to help.

Roberts, J. M. A., Keane, E., and Clark, T.R. (2012) Making Inclusion Work. Effective Inclusion Strategies. Autism Spectrum Australia's Satellite Class Project. International Journal of Inclusive Education, vol. 16. 